BIODIK: Jurnal IImiah Pendidikan Biologi
ISSN 2580-0922 (online), ISSN 2460-2612(print)
Volume 7, Nomor 01, Tahun 2021, Hal. 95-101
Available online at:
https://online-journal.unja.ac.id/biodik

Research Article OPEN ACCESS

\title{
Pengaruh Penggunaan Media Pembelajaran Flipchart terhadap Hasil Belajar Kognitif Siswa Kelas X SMA Negeri 24 Maluku Tengah
}

\section{(The Effect of Using Flipchart Learning Media on Cognitive Learning Outcomes of Class X Students of SMA Negeri 24 Maluku Tengah)}

\author{
Calvin Talakua*, Febiayu Aloatuan \\ Program Studi Pendidikan Biologi, Jurusan MIPA, STKIP Gotong Royong Masohi \\ JIn. Transeram Belakang Negeri Haruru, Kota Masohi Kabupaten Maluku Tengah \\ Coressponding Authors: talakua_calvin@yahoo.co.id
}

\begin{tabular}{|c|c|}
\hline Informasi Artikel & ABSTRACT \\
\hline $\begin{array}{l}\text { Submit: } 11-01-2021 \\
\text { Diterima: } 10-03-2021 \\
\text { Dipublikasikan: } 16-03-2021\end{array}$ & 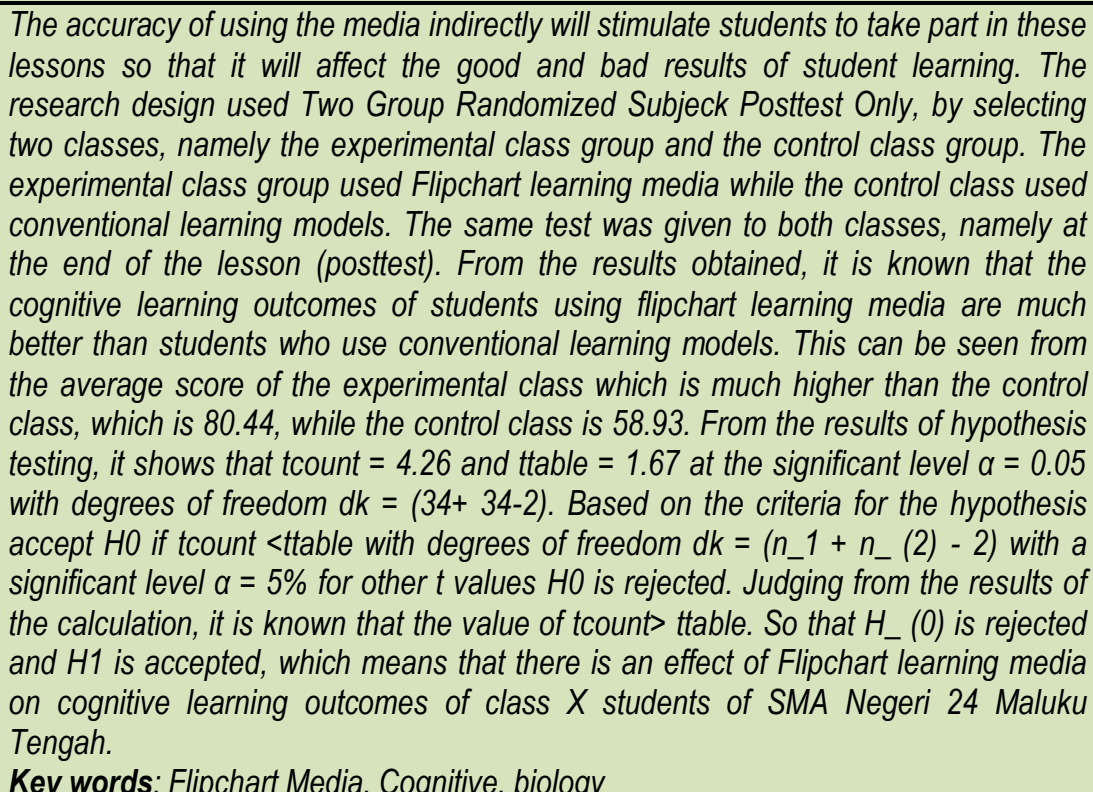 \\
\hline Penerbit & ABSTRAK \\
\hline $\begin{array}{l}\text { Program Studi Pendidikan } \\
\text { Biologi, Fakultas Keguruan dan } \\
\text { Ilmu Pendidikan, Universitas } \\
\text { Jambi }\end{array}$ & $\begin{array}{l}\text { Ketepatan penggunaan media secara tidak langsung akan menimbulkan rangsangan } \\
\text { dari diri siswa untuk mengikuti pelajaran tersebut sehingga akan mempengaruhi baik } \\
\text { buruknya hasil belajar siswa. Desain penelitian ini menggunakan Two Group } \\
\text { Randomized Subjeck Posttest Only, dengan memilih dua kelas yaitu kelompok } \\
\text { kelas eksperimen dan kelompok kelas kontrol. Kelompok kelas eksperimen } \\
\text { menggunakan media pembelajaran Flipchart sedangkan kelas kontrol } \\
\text { menggunakan model pembelajaran konvensional. Tes yang sama diberikan } \\
\text { pada kedua kelas yaitu pada akhir pembelajaran (postes). Dari hasil yang } \\
\text { didapat diketahui hasil belajar kognitif siswa yang menggunakan media } \\
\text { pembelajaran Flipchart jauh lebih baik daripada siswa yang menggunakan model } \\
\text { pembelajaran konvensional. Hal ini dilihat dari rata-rata skor kelas eksperimen } \\
\text { yang jauh lebih tinggi dari kelas kontrol yaitu } 80.44 \text { sedangkan kelas kontrol } \\
58,93 \text {. Dari hasil pengujian hipotesis menunjukan bahwa thitung }=4.26 \text { dan ttabel } \\
=1.67 \text { pada taraf singnifikan } \alpha=0,05 \text { dengan derajat kebebasan dk }=(34+34 \\
-2 \text { ). Berdasarkan kriteria hipotesis terima } H 0 \text { jika thitung }<\text { tabel dengan derajat } \\
\text { kebebasan dk }=\left(n_{1}+n_{2}-2 \text { ) dengan taraf signifikan } \alpha=5 \% \text { untuk nilai } t\right. \\
\text { lainnya H0 ditolak. Dilihat dari hasil perhitungan yang didapat diketahui nilai }\end{array}$ \\
\hline
\end{tabular}




\section{PENDAHULUAN}

Media pembelajaran merupakan salah satu komponen yang mempunyai peranan penting dalam pembelajaran. Pembelajaran berkualitas akan mendorong siswa memperoleh hasil belajar yang maksimal. Hasil belajar merupakan indikator pemahaman siswa terhadap isi pelajaran. Ketepatan penggunaan media secara tidak langsung akan menimbulkan rangsangan dari diri siswa untuk mengikuti pelajaran tersebut sehingga akan mempengaruhi baik buruknya hasil belajar siswa. Dengan kata lain media pembelajaran memiliki kontribusi terhadap hasil belajar siswa. Prestasi belajar biologi siswa yang belum memuaskan selama ini, salah satunya dipengaruhi oleh faktor tidak adanya motivasi atau keinginan siswa untuk mempelajari biologi, sehingga biologi selalu menjadi momok yang menakutkan bagi siswa, selain itu daya ingat siswa juga dirasakan sangat kurang, dikarenakan ilmu yang ditransfer tidak diulangi setelah guru memberikan pelajaran.

Proses pembelajaran yang berlangsung cenderung berpusat pada guru (teacher centered), metode yang digunakan dalam kegiatan pembelajaran kurang bervariasi sehingga siswa tidak dapat mengembangkan kemampuan yang dimilikinya dan membuat siswa kurang mempunyai kemandirian belajar dalam mengikuti kegiatan belajar mengajar. Dalam suatu proses belajar mengajar, dua unsur yang sangat penting adalah metode mengajar dan media pembelajaran. Kedua aspek ini saling berkaitan. Pemilihan salah satu metode mengajar tertentu akan mempengaruhi jenis media pembelajaran yang sesuai, meskipun masih ada berbagai aspek lain yang harus diperhatikan dalam memilih media pembelajaran.

Menurut Hamalik dalam Azhar Arsyat mengemukan bahwa pemakaian media pembelajaran dalam proses belajar mengajar dapat membangkitkan keinginan dan minat yang baru, membangkitkan motivasi dan rangsangan kegiatan belajar, dan bahkan membawa pengaruh-pengaruh psikologis terhadap siswa. Penggunaan media pembelajaran pada tahap orientasi pembelajaran akan sangat membantu keefektifan proses pembelajaran dan penyampaian pesan dan isi pelajaran pada saat itu. Selain membangkitkan motivasi dan minat siswa, media pembelajaran juga dapat membantu siswa meningkatkan pemahaman.

Kondisi yang penulis jelaskan diatas ternyata juga ditemukan pada lokasi penelitian. Berdasarkan hasil wawancara dengan guru mata pelajaran biologi pada tanggal 19 Oktober 2019, di SMA Negeri 24 Maluku Tengah, ditemukan kondisi pembelajaran secara umum yaitu kurangnya penggunaan media pembelajaran dari Guru, Guru cenderung mentransfer pengetahuan yang sumbernya hanya dari buku teks tanpa mengintegrasikan dengan kondisi terkini, sehingga hasil belajar kognitif siswa masih kurang terhadap media pembelajaran, serta Guru Biologi umumnya lebih banyak menyampaikan informasi berupa fakta, konsep, dari pada menyampaikan masalah dalam kelompok kecil.

Hasil analisis yang terjadi pada hasil ulangan MID semester ganjil tahun 2018/2019 menunjukan bahwa siswa kelas X mencapai nilai KKM (70) sebesar 50,25. Hal ini terjadi karena ketidakmampuan siswa memahami bagian paling sederhana dari materi biologi yang diajarkan guru. 
Agar kemampuan pemahaman konsep biologi siswa meningkat, perlu dilakukan perbaikan aktivitas pembelajaran di kelas.

Salah satu media yang digunakan dalam pembelajaran biologi adalah FlipChart yang cocok untuk materi keanekaragaman hayati. Media FlipChart merupakan salah satu media cetak yang sangat sederhana dan efektif. Sederhana dilihat dari proses pembuatanya dan penggunaannya yang relative mudah (Chandrasegaran, 2008). Arsyad (2014) menjelaskan bahwa FlipChart dalam pembelajaran biologi adalah media yang dapat digunakan sebagai media pembelajaran yang menyadiakan informasi yang berisi tentang gambar-gambar dan huruf-huruf. Menurut Mustaji media flipchart adalah salah satu jenis media yang penyajikannya sangat sederhana yaitu berukuran $50-75$ berisi gambar, huruf, angka berkaitan dengan materi yang diajarkan. Untuk melihat flipchart direncanakan tempat yang sesuai dimana dan bagaimana flipchart ditempatkan misalnya: dipajang di papan tulis harus terbaca oleh semua siswa. Sedangkan menurut Suyatno media flipchart adalah kumpulan ringkasan, skema, gambar, tabel yang dibuka secara berurutan berdasarkan topik materi pembelajaran. Bahan flipchart biasanya kertas yang mudah dibuka-buka, mudah ditulisi, dan berwarna cerah. Untuk daya tarik, flipchart dapat dicetak dengan aneka warna dan variasi desain. Jadi media Flipchart adalah media yang menyerupai white boart tetapi bisa di pindah kemana-mana dan bisa dibolak-balik seperti kalender sehingga mudah untuk mempergunakannya, baik dalam pembelajaran di dalam maupun diluar kelas.

Beberapa penelitian terdahulu yang relevan dengan penelitian ini adalah Rosita (2017) mengatakan bahwa, pengembangan media pembelajaran FlipChart pada materi jamur untuk siswa kelas Menurut Herditiya (2018) mengatakan bahwa pengaruh penggunaan media FlipChart terhadap hasil dan aktivitas belajar siswa kelas $\mathrm{x}$ materi fungi SMA Kemala Bhayangkari. Hal ini menunjukan bahwa media FlipChart akan memudahkan siswa memahami konsep yang diberikan oleh guru, menambah ketertarikan siswa dalam belajar, serta meningkatkan minat belajar dan hasil belajar siswa.

\section{METODE PENELITIAN}

Penelitian ini berlokasi di SMA Negeri 24 Maluku Tengah, Kecamatan Kota Masohi Kabupaten Maluku Tengah, Pada tanggal 2 februari sampai tanggal 28 februari 2020. Desain penelitian ini menggunakan Two Group Randomized Subjeck Posttest Only, dengan memilih dua kelas yaitu kelompok kelas eksperimen dan kelompok kelas kontrol. Kelompok kelas eksperimen menggunakan media pembelajaran Flipchart sedangkan kelas kontrol menggunakan model pembelajaran konvensional. Tes yang sama diberikan pada kedua kelas yaitu pada akhir pembelajaran ( postes). Desain penelitian Two Group Randomized Subjeck Posttest Only pada penelitian ini ditunjukan dalam tabel 1.

Tabel 1. desain penelitian

\begin{tabular}{lcc}
\hline Kelompok & Perlakuan & Postes \\
\hline Eksperimen ( R) & $X_{E}$ & $\mathrm{~T}$ \\
\hline Kontrol ( R ) & $X_{K}$ & $\mathrm{~T}$ \\
\hline Azizah $(2011: 38)$ & &
\end{tabular}

Keterangan :

$X_{E}=$ Perlakuan terhadap objek berupa kegiatan belajar dengan menggunakan media pembelajaran Flipchart

$X_{K}=$ Perlakuan terhadap objek berupa kegiatan belajar dengan menggunakan model pembelajaran konvensional

$\mathrm{T}=$ Tes yang diberikan pada kedua kelompok

$\mathrm{R}=$ Pengambilan sampel secara random 
Pengambilan sampel dalam penelitian ini menggunakan teknik Cluster Random Sampling, yaitu teknik pengambilan sampel dengan mengambil dua kelas secara acak dari 4 kelas yang memiliki karakteristik yang sama. Satu kelas yang akan menjadi kelas eksperimen sebanyak 34 siswa yang berasal dari kelas X1 dengan menggunakan media pembelajaran Flipchart dan satu kelas lagi menjadi kelas kontrol sebanyak 34 siswa yang berasal dari kelas X4 dengan menggunakan model pembelajaran konvensional.

Dalam penelitian ini teknik pengumpulan data yang digunakan adalah metode tes, baik dalam pembelajaran media pembelajaran Flipchart maupun dengan pembelajaran konvensional. Tes ini digunakan untuk mengukur kemampuan siswa dalam memahami materi yang diberikan. Tes yang digunakan dalam penelitian ini adalah tes hasil belajar kognitif yang berbentuk uraian, tes diberikan sesudah pembelajaran (postes) pada kelas eksperimen dan kelas kontrol.

\section{HASIL PENELITIAN DAN PEMBAHASAN}

Data yang diperoleh sebelum diolah terlebih dahulu dilakukan pemberian skor pada lembar jawaban sesuai dengan rubrik pemberian skor tes hasil belajar kognitif siswa. Dari hasil yang didapat diketahui hasil belajar kognitif siswa yang menggunakan media pembelajaran Flipchart jauh lebih baik daripada siswa yang tidak menggunakan media pembelajaran Flipchart. Hal ini dilihat dari rata-rata skor kelas eksperimen yang jauh lebih tinggi dari kelas kontrol yaitu 80.44 sedangkan kelas kontrol 58,93. Sebelum dilakukan dengan pengujian hipotesis, terlebih dahulu dilakukan pengujian prasyaratan analisis data.

\section{Uji normalitas data}

Uji normalitas dilakukan untuk mengetahui apakah data yang didapat berdistribusi normal atau tidak. Rekapitulasi hasil uji normalitas data pada kelas eksperimen dan kelas kontrol dapat dilihat pada tabel 2.

Tabel 2. Rekepitilasi hasil uji normalitas data

\begin{tabular}{lllll}
\hline No & Kelas & $\mathbf{X}^{2}$ hitung & $\mathbf{X}^{2}$ tabel & Kesimpulan \\
\hline $\mathbf{1}$ & Eksperimen & -91.2409 & 7.8150 & Normal \\
\hline $\mathbf{2}$ & Kontrol & -115.47 & 7.8150 & Normal \\
\hline
\end{tabular}

Berdasarkan tabel diatas diketahui uji normalitas data nilai $X^{2}$ hitung pada kelas eksperimen adalah -91.2409 dan kelas kontrol adalah -115.47 . Sesuai dengan kriteria uji normalitas data, Terima $\mathrm{HO}$ atau Sampel berasal dari populasi yang berdistribusi normal jika $x^{2}$ hitung $<x^{2}$ tabel dengan $\mathrm{dk}=\mathrm{k}-3$ dan taraf signifikan 5\%. Diketahui nilai $x^{2}$ tabel dengan $\mathrm{dk}$ $=6-3$ dan taraf signifikan 5\% adalah 7.8150. Sehingga dapat dilihat nilai $x^{2}$ hitung untuk kelas eksperimen dan kelas kontrol lebih kecil dari nilai $x^{2}$ tabel sehingga dapat disimpulkan kedua sampel tersebut berdistribusi normal.

\section{Uji homogenitas data}

Uji homogenitas data digunakan untuk mengetahui apakah data tersebut mempunyai varian yang sama (homogen) atau tidak. Uji kesamaan dua varian data dilakukan dengan pembagian antara varian terbesar dengan varian terkecil. Data hasil perhitungan uji homogenitas kedua sampel penelitian dapat dilihat pada tabel 3 . 
Tabel 3. Data Hasil Perhitungan Homogenitas

\begin{tabular}{lllll}
\hline No & Kelas & F $_{\text {hitung }}$ & $\boldsymbol{F}_{\text {tabel }}$ & Keterangan \\
\hline $\mathbf{1}$ & Eksperimen & & & \\
\hline $\mathbf{2}$ & Kontrol & 1.23 & 2.07 & Homogen
\end{tabular}

Berdasarkan data perhitungan pada tabel diatas dapat dilihat nilai $F_{\text {hitung }}$ kedua sampel adalah 1.23 dan $F_{\text {tabel }}$ yaitu $F \frac{1}{2} \alpha\left(n_{1}-1, n_{2}-1\right)$ adalah 2.07. Kriteria pengujian homogenitas dalam penelitian ini adalah terima $\mathrm{H}_{0}$ atau kedua sampel memiliki varians yang homogen jika $F_{\text {hitung }}<F_{\text {tabel. }}$ Dapat dilihat dari tabel diatas nilai $F_{\text {hitung }}$ lebih kecil daripada $F_{\text {tabel }}$ sehingga dapat disimpulkan kedua sampel berasal dari populasi yang homogen.

\section{Pengujian hipotesis penelitian}

Pengujian hipotesis dalam penelitian ini adalah ada pengaruh media pembelajaran Flipchart terhadap hasil belajar kognitif siswa kelas X SMA Negeri 24 Maluku Tengah. Dari hasil pengujian hipotesis menunjukan bahwa $t_{\text {hitung }}=4.26$ dan $t_{\text {tabel }}=1.67$ pada taraf singnifikan $\alpha=$ 0,05 dengan derajat kebebasan $\mathrm{dk}=(34+34-2)$. Berdasarkan kriteria hipotesis terima $\mathrm{HO}$ jika $t_{\text {hitung }}<t_{\text {tabel }}$ dengan derajat kebebasan $\mathrm{dk}=\left(n_{1}+n_{2}-2\right)$ dengan taraf signifikan $\alpha=5 \%$ untuk nilai t lainnya $\mathrm{HO}$ ditolak. Dilihat dari hasil perhitungan yang didapat diketahui nilai $t_{\text {hitung }}>t_{\text {tabel }}$ Sehingga demikian $H_{0}$ ditolak dan $\mathrm{H}_{1}$ diterima yang artinya bahwa ada pengaruh media pembelajaran Flipchart terhadap hasil belajar kognitif siswa kleas X SMA Negeri 24 Maluku Tengah.

Menurut (Sadiman, 2010) media merupakan segala sesuatu yang dapat dipakai untuk mengantarkan pesan. Pesan yang disampaikan adalah isi pembelajaran dalam bentuk tema atau topic pembelajaran dengan tujuan agar terjdi proses belejar dalam diri anak.Sehingga dapat dikatakan bahwa media pembelajaran merupakan suatu perantara yang digunakan oleh guru untuk mempermuda guru dalam berkomunikasi dengan peserta didik. Adapun beberapa fungsi media dalam pembelajaran yaitu memperjelas penyajian pesan agar tidak terlalu dalam bentuk kata-kata tertuli atau lisan belaka dan mengatasi sikap pasif peserta didik, yaitu dapat menimbulkan gairah belajar, memukinkan interaksi yang lebi langsung antara peserta didik dengan lingkungan dan kenyatannya serta memungkinkan peserta didik belajar sendiri menurut kemampuan dan minatnya.

Media FlipChart merupakan salah satu media cetak yang sederhana dan cukup efektif. Penggunaan FlipChart merupakan salah satu cara guru dalam menghemat waktu terutama untuk menulis dipapan tulis. Melalui penggunaan media pembelajaran bagi siswa maka mampu menyajikan pesan pembelajaran secara ringkas dan praktis. Sedangkan menurut Daryanto (2012) media flipchart adalah kumpulan ringkasan, skema, gambar, tabel yang dibuka secara berurutan berdasarkan topik materi pembelajaran. Bahan flipchart biasanya kertas yang mudah dibuka-buka, mudah ditulisi, dan berwarna cerah. Untuk daya tarik, flipchart dapat dicetak dengan aneka warna dan variasi desain. Jadi media Flipchart adalah media yang menyerupai white boart tetapi bisa di pindah kemana-mana dan bisa dibolak-balik seperti kalender sehingga mudah untuk mempergunakannya, baik dalam pembelajaran di dalam maupun diluar kelas. Sebagai salah satu media pembelajaran, Flipchart memiliki beberapa kelebihan, diantaranya: mampu menyajikan pesan pembelajaran secara ringkas dan praktis, dapat menggunakan di dalam ruangan atau luar ruangan, bahan pembuatan relatif murah, mudah dibawa kemana-mana (moveable) karena berukuran antara 60 sampai $75 \mathrm{~cm}$, maka menjadi mudah untuk dibawa ke tempat yang dibutuhkan, dan mampu meningkatkan aktivitas belajar siswa. 


\section{KESIMPULAN}

Berdasarkan analisis data dan hasil pembahasan dapat diperoleh kesimpulan yaitu penggunaan media pembelajaran FlipChart berpengaruh terhadap hasil belajar kognitif siswa kelas $\mathrm{X}$ SMA Negeri 24 Maluku Tengah. Melalui penggunaan pembelajaran FlipChart maka hasil belajar siswa dapat ditingkatkan. Siswa dapat mengakses materi pembelajaran dan informasi dari mana saja dan kapan saja. Melalui pembelajaran FlipChart dapat mengatasi permasalahan yang dihadapi guru di SMA Negeri 24 Maluku Tengah dan juga mengatasi permasalahan pembelajaran ditengah kondisi pandemi saat ini. Penggunaan FlipChart pada pelajaran biologi tidak di melulu di gunakan setiap tatap muka, tapi sebagian besar tatap muka menggunakan flipchart karena dianggap lebih efektif daripada hanya menjelaskan dari buku saja. Untuk mencapai target yang diinginkan ada berbagai macam cara guru untuk mencari flipchart, cara yang paling mudah adalah guru membeli media FlipChart kosong dan di beri butiran-butiran penjelasan yang ditulis atau gambar dengan penjelasan yang singkat, padat dan jelas tentunya. Selain itu untuk mempersiapkan FlipChart pada proses pembelajaran mata pelajaran biologi guru juga mencoba membuat media FlipChart sederhana yang di buat sendiri karena banyaknya materi yang ingin dijelaskan dengan FlipChart. Setelah flipchart selesai dibuat atau dirancang guru akan menggunakannya sesuai dengan jadwal dan kebutuhannya.

\section{UCAPAN TERIMA KASIH}

Peneliti mengucapkan terima kasih yang sebesar-besarnya kepada :

1. Kalsum Sehulawano, S.Pdl., M.Pd selaku Ketua STKIP Gotong Royong Masohi yang telah memberi motivasi dan dorongan dalam penelitian ini.

2. Kepala Sekolah SMA Negeri 24 maluku Tengah yang telah membantu dan berkontribusi dalam pelaksanaan penelitian ini.

3. Marlen Sahureka, S.Si., M.Sc selaku Ketua LPPM yang telah berkontribusi dalam membantu pelaksanaan penelitian ini.

\section{DAFTAR PUSTAKA}

Arsyad, A. (2013). Media pengajaran. Raja Grafindo.

Arikunto, S. (2010). Prosedur Penelitian. PT Rineka Cipta.

Arifin, Z. (2012). Penelitian Pendidikan Metode dan Paradigma Baru. Rusda.

Chandrasegaran, A. L., Treagust, D. F. dan Mocerino, M. (2008). An Evaluation of a Teaching

Intervention to Promote Students' Ability to Use Multiple Levels of Representation When

Describing and Explaining Chemical Reaction"s. Research in Science Education, 38(2), 237-248.

Daryanto, (2012)Media Pembelajaran, Satu Nusa: Bandung.

Hake, R. . (2004). Design-Based Research: A Primer for Physics Education Researchers. The American Journal of Physics, 2(1).

Hirsh-Pasek, K., Zosh, J.M., Golinkoff, R.M., Gray, J.H., Robb,M.B., dan Kaufman, J. (2015). Putting Education in "Educational" apps: Lessons From teh Science of Learning. Psychological Science in the Public Interest, 16(1), 3-34.

Musfiqo. (2012). Pengembangan Media dan Sumber Pembelajaran. PT Prestasi Pustakarya.

Munadi, Y. (2010). Media Pembelajara. GP Press group.

Nurhamzah Asep Andi Rahman. (2016). Penerapan media Visual Flipchart untuk meningkatkan

kemampuan memecahkan masalah siswa pada mata pelajaran pendidikan Agama Islam. Journal of Chemical Information and Modeling, 1(1), 1437. 
https://doi.org/10.1017/CB09781107415324.004

Pratiwi, D. E., \& Mulyani. (2013). Penerapan Media Papan Balik (Flipchart) Pada Pembelajaran Tematik Untuk Meningkatkan Hasil Belajar Siswa Sekolah Dasar. Jurnal JPGSD, Program Studi S-1 PGSD, Fakultas IImu Pendidikan UNESA, Surabaya, Volume 01(296), 10. http://files/493/Pratiwi 2013 - Penerapan Media Papan Balik (Flipchart) Pada Pembelajaran.pdf

Safitri, A., \& Marjo, H. K. (2019). Pengembangan Media Pembelajaran Visual dengan Menggunakan Flipchart untuk Meningkatkan Motivasi Berprestasi Melalui Layanan Bimbingan Kelompok. INSIGHT: Jurnal Bimbingan Konseling, 7(2), 185-194. https://doi.org/10.21009/insight.072.08 Susanto, A. (2013). Teori Belajar dan Pembelajaran. PT Kharisma Putra Utama.

Trianto. (2011). Mendesain Model Pembelajaran InovatifProgresi. Kencana Prenada Media Group. Utami, Y. (2012). Penerapan Media Flipchart Dalam Pembelajaran Tematik Untuk Meningkatkan Hasil Belajar Siswa Kelas II SDN Lidah Kulon III/466. In UNESA (Ed.), Skripsi Tidak Diterbitkan. 